\title{
Patterns of initiation of second generation antipsychotics for bipolar disorder: a month-by-month analysis of provider behavior
}

\author{
Christopher J Miller ${ }^{1 *}$, Mingfei Li $i^{1,3 \dagger}$, Robert B Penfold ${ }^{4,5 \dagger}$, Austin F Lee ${ }^{1,3,6,7 \dagger}$, Eric G Smith ${ }^{1,8 \dagger}$, David N Osser ${ }^{9 \dagger}$,
} Laura Bajor ${ }^{1 \dagger}$ and Mark S Bauer, ${ }^{1,2+}$

\begin{abstract}
Background: Several second generation antipsychotics (SGAs) received FDA approval for bipolar disorder in the 2000s. Although efficacious, they have been costly and may cause significant side effects. Little is known about the factors associated with prescribers' decisions to initiate SGA prescriptions for this condition.

Methods: We gathered administrative data from the Department of Veterans Affairs on 170,713 patients with bipolar disorder between fiscal years 2003-2010. Patients without a prior history of taking SGAs were considered eligible for SGA initiation during the study ( $n=126,556)$. Generalized estimating equations identified demographic, clinical, and comorbidity variables associated with initiation of an SGA prescription on a month-by-month basis.

Results: While the number of patients with bipolar disorder using SGAs nearly doubled between 2003 and 2010, analyses controlling for patient characteristics and the rise in the bipolar population revealed a 1.2\% annual decline in SGA initiation during this period. Most medical comorbidities were only modestly associated with overall SGA initiation, although significant differences emerged among individual SGAs. Several markers of patient severity predicted SGA initiation, including previous hospitalizations, psychotic features, and a history of other antimanic prescriptions; these severity markers became less firmly linked to SGA initiation over time. Providers in the South were somewhat more likely to initiate SGA treatment.
\end{abstract}

Conclusions: The number of veterans with bipolar disorder prescribed SGAs is rising steadily, but this increase appears primarily driven by a corresponding increase in the bipolar population. Month-by-month analyses revealed that higher illness severity predicted SGA initiation, but that this association may be weakening over time.

Keywords: Bipolar disorder, Antipsychotics, Veterans

\section{Background}

Bipolar disorder is associated with high morbidity, mortality, health care costs, and risk of suicide [1-3]. Beginning in the 1960's, lithium emerged as the frontline treatment for this disorder [4], with anticonvulsants like carbamazepine [5] and valproate [6] expanding the armamentarium. More recently, several second-generation antipsychotics (SGAs) have received FDA approval and guideline endorsement for various phases of bipolar disorder including

\footnotetext{
*Correspondence: christopher.miller8@va.gov

${ }^{+}$Equal contributors

'The Center for Healthcare Organization and Implementation Research, VA Boston Healthcare System and Edith Nourse Rogers Memorial VA Medical Center, Bedford, MA, USA

Full list of author information is available at the end of the article
}

mania, depression, and mixed states [7-10], with further support from meta-analyses [11-14]. Some treatment guidelines, in fact, go further in recommending SGAs as frontline treatments for mania and bipolar depression $[15,16]$. The number of annual SGA prescriptions for bipolar disorder now rivals that written for lithium and valproate combined [17]. However, several SGAs have concerning cardiometabolic side effect profiles [18-21] and they have been among the most costly classes of medications in the U.S. [22].

Little research has investigated the factors affecting providers' decisions to prescribe SGAs in this population. Patient-based studies of mixed diagnostic groups have found inconsistent results regarding impacts of patient 
gender [23-32], race [23-37], or age [23,25-29,31,32,35] on SGA prescribing. Fewer studies have examined clinical factors like substance use, cardiometabolic risk, or prior treatment [23-25,27-30]. Crucially, only a small subset of these studies $[33,34]$ focused on bipolar disorder specifically. More work is needed to identify the factors that affect providers' decisions to treat bipolar disorder with SGAs in order to facilitate personalization of treatment and system-level quality improvement interventions.

Accordingly, this study used national Department of Veterans Affairs (VA) data to identify demographic and clinical factors associated with the decision to initiate an SGA for bipolar disorder from 2003-2010, and also to determine whether SGAs have been used more broadly (i.e. for less severely ill patients) over time. While our primary analyses focused on SGAs as a group, we secondarily investigated predictors of initiation for individual SGAs. Our analyses were designed to assess patient characteristics on a month-by-month basis, approximating the data that a prescriber might have readily accessible in deciding whether or not to prescribe an SGA.

\section{Methods}

The VA Central Institutional Review Board approved all study procedures.

\section{Population}

We obtained administrative records from the VA Corporate Data Warehouse for fiscal years 2003-2010. All VA service users who received a diagnosis of bipolar disorder (ICD-9 code 296.xx, including bipolar type I, type II, and Not Otherwise Specified [NOS]) at one inpatient or two outpatient service contacts in a one-year period were included in the study population. Individuals with any schizophrenia spectrum diagnosis (290.0-298.9) at any point during the study period were excluded.

From this overall sample $(n=170,713)$, we identified on a month-by-month basis those patients "at risk" for SGA initiation, defined as (a) not having received an SGA prescription from the beginning of the study period to the month in question (i.e., excluding those with any prior SGA treatment from 2003 to that month), and (b) having a clinical encounter for their bipolar disorder in that month. To assess characteristics likely to impact clinical decision-making at a given point in time, this sample ( $\mathrm{n}=126,556$ unique individuals) was then characterized on a month-by-month basis regarding demographic and clinical characteristics and whether they had initiated an SGA in that month, as defined below.

Preliminary analyses also explored the number of providers prescribing SGAs within VA. Providers "at risk" for prescribing an SGA within a given month were defined as clinicians from prescribing specialties (physician, advanced practice nurse, physician's assistant, PharmD) who provided a bipolar disorder diagnosis for at least one clinical encounter that month.

\section{Definition of SGA initiation}

SGA initiation, our primary outcome, was coded dichotomously each study month. Analyses focused on the five most common oral SGAs used to treat bipolar disorder: aripiprazole, olanzapine, quetiapine, risperidone, and ziprasidone. Initial analyses investigated these medications as a group; while additional analyses assessed individual agents. Newer antipsychotics (paliperidone, iloperidone, lurasidone, asenapine), approved after 2006, were not included, nor was clozapine (due to very low prevalence within VA) [38], or injectable antipsychotics (due to a lack of adequate recording in VA administrative data).

Analyses focused on each patient's first intentional trial of an SGA during 2003-2010 [39]. Intentional trials were defined as receipt of (a) at least one 30-day outpatient prescription, or (b) at least three consecutive days of inpatient administration. Thirty days was the modal duration for outpatient prescriptions; sensitivity analyses reflected little variation in usage based on this duration (e.g. only 6-8\% of outpatient SGA prescriptions were for $<30$ days). Those initiating SGAs who were hospitalized for $<3$ days were adequately identified by 30-day outpatient prescriptions at discharge. We included any daily dose since prescribers might start a medication at lower dosages before titrating.

For each month, patients were identified as SGA initiators if they (a) had not received a previous intentional SGA trial during the study period, and (b) received an intentional trial that month for any of the five study SGAs. The comparison group of SGA non-initiators for each month was defined as all patients who (a) had not received a previous intentional SGA trial during the study period, (b) had been seen by a prescriber for bipolar disorder that month, but who (c) did not receive a prescription for an intentional SGA trial that month. For 2003 we began analyses at month seven, thus requiring at least a six-month clean period for all patients.

\section{Covariates}

\section{Demographics}

Demographic characteristics included patient age, gender, race/ethnicity, marital status, VA eligibility status $(\geq 50 \%$ VA service-connected pension, which relieves copays for clinical services), and geographic region $[40,41]$.

\section{Clinical course variables}

Bipolar type was dichotomized as bipolar type I versus bipolar type II/NOS, with bipolar I assigned if $\geq 10 \%$ of prior diagnoses were bipolar I; sensitivity analysis indicated that varying this cut-off from $10-50 \%$ resulted in little change in proportion of type I versus II/NOS. Psychotic features were identified for a given month if any diagnoses of mood 
episode with psychotic features (ICD-9 codes 296.×4) were identified over the prior year. Treatment variables included prescriptions of antidepressants and antimanic agents (lithium, anticonvulsants, first-generation antipsychotics) within the prior year. Prior hospitalization status was dichotomized as any/no prior acute mental health inpatient hospitalizations since the beginning of the study.

\section{Comorbidities}

Based on published literature, comorbidities judged to potentially affect provider decisions were coded as present if the patient received treatment for a given diagnosis in the 12 months prior to the month in question. These included substance use disorders, tobacco use disorder, anxiety disorder, sleep disorders, traumatic brain injury, diabetes, hyperlipidemia, cardiac dysrhythmia, and liver, kidney, or thyroid disorders.

\section{Establishing time-varying covariates}

Some covariates (e.g. gender, race) were treated as timeinvariant. Others (e.g. age, clinical course variables, comorbidities) were assessed on a month-to-month basis. This approach allowed us to characterize status for each patient for each study month. For instance, consider a hypothetical patient who was diagnosed as bipolar type I in January, 2004, that the case is not referring to an actual patient developed diabetes in January, 2005, and initiated aripiprazole in June, 2005. For any month in 2004 in which he was treated for bipolar disorder, he would qualify as an SGA non-initiator with bipolar type I. In 2005 he would remain a non-initiator, but would also carry a diabetes diagnosis. In June of 2006 he would qualify as an SGA initiator with bipolar type I and diabetes, and during subsequent months would be considered ineligible for initiator or non-initiator status.

\section{Data analyses}

We first calculated the annual number and rate of SGA prescriptions in the bipolar population, as well as the annual number and rate of providers writing SGA prescriptions. We used preliminary time series analyses to explore the overall change in these numbers over time.

Our primary analytic tool was multivariate generalized linear modeling (GLM) with binomial distribution and logit link function to determine rates and correlates of SGA initiation on a month-by-month basis. Generalized estimating equations (GEE) were used to account for correlations from repeated measures within patients, as an individual patient could be in the dataset at several points as non-initiator before finally initiating an SGA in a later month. This allowed us to aggregate data across all 96 study months, accounting for patients appearing in multiple consecutive or non-consecutive months as described above. All variables were entered into the model simultaneously. We then added predictor-by-time interaction terms to the GLM to investigate changes over time in SGA initiation rates for those with milder versus more severe forms of bipolar disorder, specifically: (a) bipolar type I versus II/NOS, (b) psychotic features, (c) prior psychiatric hospitalization, and (d) treatment with antimanic medications.

Finally, we used multinomial univariate regression models to determine whether several comorbid conditions, characterized on a month-by-month basis, were associated with the choice of specific SGAs. The comparison drug for these analyses was aripiprazole, which is associated with relatively mild cardiometabolic or sedative effects [42]. If a patient initiated more than one SGA, only their first initiation was included in these latter analyses.

\section{Results}

\section{Overall SGA use for bipolar disorder}

The number of patients with bipolar disorder prescribed SGAs almost doubled from 2003 to 2010 (31,779 in 2003; 61,697 in 2010; average annual increase of 4,226; $95 \% \mathrm{CI}=$ $3,752-4,699 ; p<.0001)$, including both new initiators of these medications as well as patients continuing previous prescriptions. The number of patients treated for bipolar disorder increased more modestly $(53,591$ in 2003; 85,684 in 2010). Accordingly, the proportion of bipolar patients using an SGA rose from 59.3\% in 2003 to a peak of $74.9 \%$ in 2008, followed by a slight decrease to $72.0 \%$ in 2010 (Figure 1; average $7.1 \%$ per year, $\mathrm{OR}=1.071,95 \% \mathrm{CI}=$ $1.068-1.074, p<.0001$. This increase was matched by a rise in the number of providers writing these prescriptions, ranging from 11,031 in 2003 to a peak of 15,965 in 2009, followed by a slight reduction to 15,609 in 2010 (average annual increase 556; 95\% CI $=365-747 ; p=.0007$ ). All told, out of our overall sample of 170,713 patients with bipolar

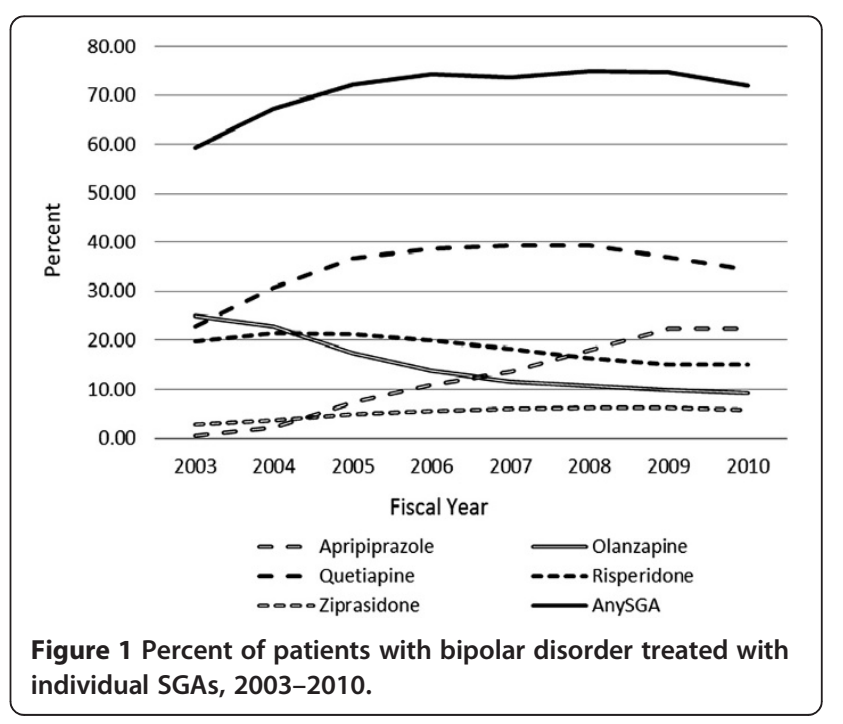


disorder, 113,510 had at least one SGA prescription written during the study period (66\%). While the number of providers writing SGA prescriptions for bipolar disorder increased, the proportion of eligible providers writing SGA prescriptions decreased slightly over the course of the study (from $90.2 \%$ in 2004 to $85.6 \%$ in 2010; annual OR $=0.927$; $95 \% \mathrm{CI}=0.918-0.936 ; p<.0001)$.

There was heterogeneity in overall use of individual SGAs, with significant average annual increases for aripiprazole (2,910 users; $95 \% \mathrm{CI}=2,505-3,316 ; \mathrm{p}<.0001)$, quetiapine $(2,427 ; 95 \% \mathrm{CI}=1,571-3,284 ; \mathrm{p}=.0004)$, and ziprasidone (534, 95\% $\mathrm{CI}=431-637 ; \mathrm{p}<.0001$ ), but a reduction for olanzapine (861 fewer annual users; $95 \% \mathrm{CI}=438-1,284$; $\mathrm{p}=.0025)$ and no change for risperidone $(138 ; 95 \% \mathrm{CI}=$ -111-386; $\mathrm{p}=.2232$ ). In terms of proportion of users, annual increases were seen for aripiprazole $(\mathrm{OR}=1.408,95 \% \mathrm{CI}=$ $1.402-1.414)$, quetiapine $(\mathrm{OR}=1.055,95 \% \mathrm{CI}=1.052-1.057)$, and ziprasidone $(\mathrm{OR}=1.092,95 \% \mathrm{CI}=1.086-1.098)$, with decreases for olanzapine $(\mathrm{OR}=0.832,95 \% \mathrm{CI}=0.829-0.834$ ) and risperidone $(\mathrm{OR}=0.934,95 \% \mathrm{CI}=0.931-0.936)$ (all $p<$ $0.0001)$.

\section{SGA initiation in bipolar disorder}

Figure 2 describes the nationwide number of patients newly initiated on an SGA each year, indicating between 5,109 and 6,745 patients entering the population of SGA users each year between 2004 and 2010 (mean $=5,951 ; 95 \% \mathrm{CI}=$ $4,685-7,217 ; p<.0001$ ). There was no significant change over time in the number of new initiators per year (annual average increase $11 ; 95 \% \mathrm{CI}=-332-355 ; p=.9374$ ). When combined with the steady increase in the population of patients with bipolar disorder, this meant that the odds of being newly initiated on an SGA actually decreased as the

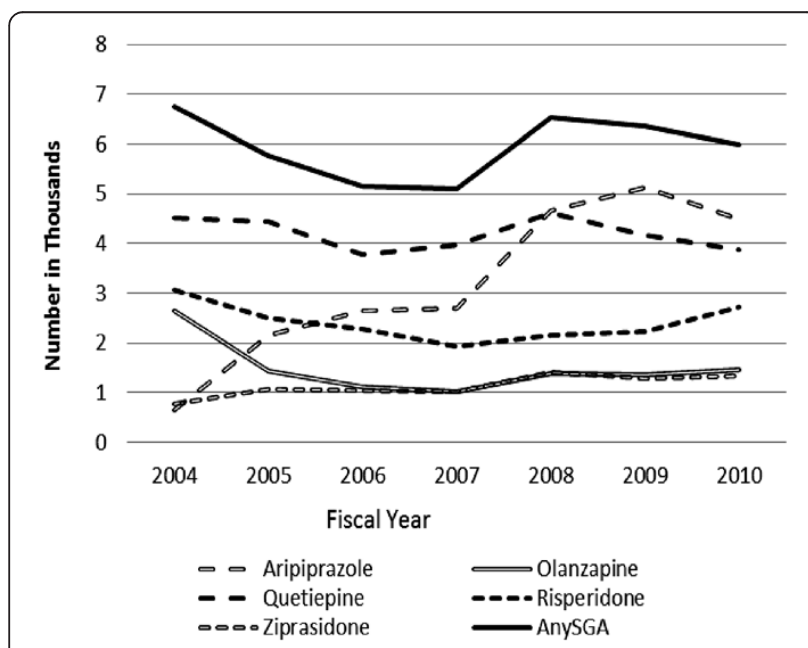

Figure 2 Patients with bipolar disorder initiating SGAs, 2004-2010. Note: Figure 2 begins with 2004 since patients were not eligible to be labeled as SGA initiators until month 7 of 2003; see Methods for details. study progressed (annual OR 0.929; 95\% CI = 0.924-0.933; $p<.0001)$.

\section{Description of the patient sample and bivariate comparisons}

Table 1 summarizes the VA bipolar population $(\mathrm{n}=170,713)$ including individuals who ever $(n=45,389)$ or never $(n=$ 81,167) initiated an SGA during the study period, yielding a primary analytic sample of 126,556. The remaining 44,157 patients entered the study taking an SGA and so were excluded from initiator analyses.

Unadjusted bivariate comparisons between SGA initiators and non-initiators using all available data during the study period (Table 1) demonstrated that nearly all characteristics had small but statistically significant associations at the $p<.0001$ level. Patients initiating an SGA during the study period were on average several years younger than noninitiators. Those initiated on an SGA were nearly twice as likely to be identified as having psychotic features, but only slightly more likely to have a bipolar type I diagnosis, substance use disorder, or anxiety disorder, with small, inconsistent impact of medical comorbidities. Patients initiated on an SGA were more likely to have been hospitalized for a psychiatric issue at least once and to receive a non-SGA antimanic prescription at least once.

\section{Month-by-month, multivariate correlates of SGA initiation}

Table 2 presents GLM findings for which, in contrast to Table 1, covariates were entered simultaneously into the model, and were coded as present only if diagnosed simultaneously or within the year prior to the month of SGA initiation. Again, small but statistically significant differences were demonstrated for most variables. Among stronger effects, female gender was associated with reduced likelihood of initiating an SGA $(\mathrm{OR}=0.846,95 \% \mathrm{CI}=0.815-0.878)$, as was disability status $(\mathrm{OR}=0.740,95 \% \mathrm{CI}=0.717-0.763)$. Compared to the Northeast, patients seen in the South were more likely to initiate an SGA $(\mathrm{OR}=1.288,95 \% \mathrm{CI}=$ $1.245-1.332)$, and those in the West less likely $(\mathrm{OR}=0.919$, 95\% CI $=0.886-0.953$ ). Patients with psychotic features were more likely to be initiated on an SGA (OR $=1.696$, $95 \% \mathrm{CI}=1.520-1.891)$. Patients with a mood stabilizer prescription in the past year were much less likely to initiate an SGA than those who had not $(\mathrm{OR}=0.620,95 \% \mathrm{CI}=$ 0.606-0.634), unlike the all-years analysis (Table 1). Patients with a sleep disorder diagnosis were more likely to initiate an SGA (OR $=1.555,95 \% \mathrm{CI}=1.435-1.685)$. Most medical comorbidities were only modestly associated with overall SGA initiation rates in our sample. GLM indicated an average reduction in the odds of SGA initiation over time $(\mathrm{OR}=0.988$ per year, $95 \% \mathrm{CI}=0.982-0.993$. When we added prior hospitalization to the model, it was also strongly associated with SGA initiation $(\mathrm{OR}=2.629$, 95\% CI $=2.546-2.713)$. 
Table 1 Description of the sample

\begin{tabular}{|c|c|c|c|c|c|c|}
\hline \multirow[b]{2}{*}{ Variable } & \multicolumn{2}{|c|}{$\begin{array}{l}\text { Bipolar population } \\
(\mathrm{N}=170,713)^{\mathrm{a}}\end{array}$} & \multicolumn{2}{|c|}{$\begin{array}{l}\text { Never initiated SGA during study period } \\
\text { ( } N=81,167,64.1 \% \text { of those eligible for } \\
\text { SGA initiation) }\end{array}$} & \multicolumn{2}{|c|}{$\begin{array}{l}\text { Ever initiated SGA during study period } \\
\text { ( } N=45,389,35.9 \% \text { of those eligible for } \\
\text { SGA initiation) }\end{array}$} \\
\hline & Mean & SD & Mean & SD & Mean & SD \\
\hline \multirow[t]{2}{*}{ Age at study entry ${ }^{b}$} & 50.3 & 13.3 & 51.6 & 13.6 & 48.3 & 13.0 \\
\hline & $\mathbf{N}$ & $\%$ & $\mathbf{N}$ & $\%$ & $\mathbf{N}$ & $\%$ \\
\hline Gender (female) & 24,076 & 14.1 & 10,804 & 13.3 & 6,954 & 15.3 \\
\hline Disability status $\geq 50 \%{ }^{c, d}$ & 52,584 & 30.9 & 23,067 & 28.5 & 13,148 & 29.0 \\
\hline Marital status ${ }^{\mathrm{d}}$ & 76,315 & 44.9 & 34,786 & 43.3 & 18,265 & 40.5 \\
\hline \multicolumn{7}{|l|}{ Race/ethnicity ${ }^{e}$} \\
\hline White & 127,742 & 82.2 & 60,381 & 83.0 & 34,425 & 82.6 \\
\hline African American & 20,884 & 13.4 & 9,305 & 12.8 & 5,588 & 13.4 \\
\hline Hispanic & 4,034 & 2.6 & 1,861 & 2.6 & 891 & 2.1 \\
\hline Other race/ethnicity ${ }^{c}$ & 2,684 & 1.7 & 700 & 1.0 & 455 & 1.1 \\
\hline \multicolumn{7}{|l|}{ Clinical/treatment course ${ }^{d}$} \\
\hline Psychotic features & 22,119 & 13.0 & 6,822 & 8.4 & 7,322 & 16.1 \\
\hline Bipolar type I (versus type II/NOS) ${ }^{f}$ & 145,128 & 85.0 & 68,344 & 84.2 & 40,283 & 88.8 \\
\hline Antidepressant prescription & 139,807 & 81.9 & 55,920 & 68.9 & 34,969 & 77.0 \\
\hline Antimanic prescription & 128,596 & 75.3 & 51,820 & 63.8 & 35,755 & 78.8 \\
\hline Any psychiatric hospitalization & 64,117 & 37.6 & 23,284 & 28.7 & 21,330 & 47.0 \\
\hline \multicolumn{7}{|l|}{ Comorbidities $^{d}$} \\
\hline Diabetes & 42,517 & 24.9 & 20,679 & 25.5 & 10,138 & 22.3 \\
\hline Obesity & 61,182 & 35.8 & 27,469 & 33.8 & 16,581 & 36.5 \\
\hline Hyperlipidemia & 101,886 & 59.7 & 47,770 & 58.9 & 26,190 & 57.7 \\
\hline Substance abuse & 79,658 & 46.7 & 33,202 & 40.9 & 23,280 & 51.3 \\
\hline Tobacco use disorder & 86,311 & 50.6 & 37,406 & 46.1 & 24,182 & 53.3 \\
\hline Anxiety disorder & 102,130 & 59.8 & 43,310 & 53.4 & 27,331 & 60.2 \\
\hline Sleep disorder & 29,355 & 17.2 & 11,762 & 14.5 & 8,072 & 17.8 \\
\hline Cardiac dysrhythmia & 19,600 & 11.5 & 9,509 & 11.7 & 4,827 & 10.6 \\
\hline Liver disorder & 22,332 & 13.1 & 9,460 & 11.7 & 5,997 & 13.2 \\
\hline Kidney disorder & 19,044 & 11.2 & 9,271 & 11.4 & 4,729 & 10.4 \\
\hline Thyroid disorder ${ }^{c}$ & 20,226 & 11.9 & 9,429 & 11.6 & 5,566 & 12.3 \\
\hline Traumatic brain injury & 9,209 & 5.4 & 3,629 & 4.5 & 2,557 & 5.6 \\
\hline
\end{tabular}

Includes data on those patients ineligible to be labeled as SGA initiator or SGA non-initiator $(\mathrm{N}=44,157)$.

bUnless otherwise stated, all comparisons between the ever-initiated and never-initiated groups were $p<.0001$.

${ }^{\mathrm{C}}$ For these variables, comparison between the ever-initiated and never-initiated groups was $p>.0001$ ( $>50 \%$ disability status: $p=.0385$; other race/ethnicity:

$p=.0120$; thyroid disorder, $p=.0006$ ).

dUnless otherwise stated, these variables were coded as present if they occurred at any point during the study period.

eBased on smaller $\mathrm{N}$, due to missing values for $9 \%$ of the sample.

${ }^{f}$ At patient's last available data during the study period.

\section{The role of clinical complexity in SGA initiation rates over time}

We hypothesized $a$ priori that SGAs were being initiated for an increasingly diverse population over time. Variable-bytime interaction terms for several indicators of severity (selected $a$ priori) were added to the GLM. These analyses indicated that, over successive years, SGA initiation became increasingly common for individuals with: type II/
NOS (beta $=0.0168, Z=2.34, p=.0219$ ), no antimanic prescription in the past year (beta $=0.0396, Z=7.98$, $p<.0001$ ), and no previous psychiatric hospitalization (beta $=0.07, Z=12.78, p<.0001$ ), although not for those without psychotic features (beta $=0.0168, Z=0.83$, $p=.4196)$. Taken together, these results indicate that, over time, patients with less severe bipolar disorder (as marked by an absence of previous hospitalizations, 
Table 2 Results from GLM predicting SGA initiation

\begin{tabular}{|c|c|c|c|c|}
\hline Variable & Odds ratio & $95 \% \mathrm{Cl}$ - lower & $95 \% \mathrm{Cl}$ - upper & $p$ \\
\hline Age (decade) & 0.997 & 0.997 & 0.997 & $<.0001$ \\
\hline Gender (female) & 0.846 & 0.815 & 0.878 & $<.0001$ \\
\hline$\geq \mathbf{5 0} \%$ disability status & 0.740 & 0.717 & 0.763 & $<.0001$ \\
\hline Marital status (married) & 1.011 & 0.985 & 1.039 & .4062 \\
\hline \multicolumn{5}{|l|}{ Race/ethnicity ${ }^{a}$} \\
\hline African American & 1.068 & 1.024 & 1.114 & .0021 \\
\hline Hispanic & 0.989 & 0.901 & 1.087 & .8222 \\
\hline Other race/ethnicity & 1.096 & 0.964 & 1.246 & .1614 \\
\hline \multicolumn{5}{|l|}{ Region $^{b}$} \\
\hline Midwest & 0.991 & 0.955 & 1.028 & .6221 \\
\hline South & 1.288 & 1.245 & 1.332 & $<.0001$ \\
\hline West & 0.919 & 0.886 & 0.953 & $<.0001$ \\
\hline \multicolumn{5}{|c|}{ Clinical/treatment factors in prior year } \\
\hline Psychotic features & 1.696 & 1.520 & 1.891 & $<.0001$ \\
\hline Bipolar type I (versus type II/NOS) ${ }^{c}$ & 0.968 & 0.935 & 1.003 & .0736 \\
\hline Antidepressant prescription & 0.903 & 0.882 & 0.924 & $<.0001$ \\
\hline Antimanic prescription & 0.620 & 0.606 & 0.634 & $<.0001$ \\
\hline \multicolumn{5}{|l|}{ Comorbidities in prior year } \\
\hline Diabetes & 0.919 & 0.882 & 0.957 & $<.0001$ \\
\hline Obesity & 0.958 & 0.913 & 1.004 & .0739 \\
\hline Hyperlipidemia & 0.991 & 0.960 & 1.023 & .5860 \\
\hline Substance abuse & 0.965 & 0.933 & 0.999 & .0407 \\
\hline Tobacco use disorder & 1.065 & 1.030 & 1.103 & .0003 \\
\hline Anxiety disorder & 1.082 & 1.051 & 1.114 & $<.0001$ \\
\hline Sleep disorder & 1.555 & 1.435 & 1.685 & $<.0001$ \\
\hline Cardiac dysrhythmia & 1.096 & 0.999 & 1.202 & .0520 \\
\hline Liver disorder & 1.145 & 1.079 & 1.214 & $<.0001$ \\
\hline Kidney disorder & 1.187 & 1.069 & 1.318 & .0014 \\
\hline Thyroid disorder & 1.021 & 0.956 & 1.089 & .5372 \\
\hline Traumatic brain injury & 1.109 & 0.944 & 1.303 & .2068 \\
\hline Change per year & 0.988 & 0.982 & 0.993 & $<.0001$ \\
\hline
\end{tabular}

${ }^{\mathrm{a} C o m p a r i s o n: \text { White. }}$

${ }^{\mathrm{b} C o m p a r i s o n: ~ N o r t h e a s t . ~}$

CPatient was labeled as bipolar type I for a given month if at least $10 \%$ of bipolar encounters to date were for bipolar type I. See text for details.

psychotic features, antimanic prescriptions, and bipolar type I diagnoses) represented an increasing share of new SGA initiations.

\section{Association of comorbidities with specific SGAs}

Consistent with a priori hypotheses, diabetes, obesity, and hyperlipidemia were associated with decreased odds of initiating olanzapine, quetiapine, or risperidone compared to aripiprazole (ORs ranging from 0.352 to 0.856 , all $p<.0003$ ) (Table 3). Cardiac dysrhythmia was associated with a trend toward lower likelihood of initiating ziprasidone $(\mathrm{OR}=0.725,95 \% \mathrm{CI}=0.505-1.042, p=.0825)$.
Individuals with substance use disorders were more likely to initiate olanzapine $(\mathrm{OR}=1.321,95 \% \mathrm{CI}=1.230-1.417$, $p<.0001)$ or quetiapine ( $\mathrm{OR}=1.363,95 \% \mathrm{CI}=1.288$ $1.442, p<.0001)$. Those with comorbid sleep disorder did not significantly differ in use of any SGAs with the exception of risperidone $(\mathrm{OR}=0.794,95 \% \mathrm{CI}=0.654-0.965$, $p=.0204)$.

\section{Discussion}

This study revealed several core findings. First, SGA use for bipolar disorder is increasing within VA medical centers, with an average of about 6,000 new SGA initiations 
Table 3 Multinomial regressions for initiation of individual SGAs, compared to aripiprazole

\begin{tabular}{|c|c|c|c|c|c|c|c|c|c|c|c|c|c|c|c|c|}
\hline \multirow[b]{2}{*}{$\begin{array}{l}\text { Comorbidity in } \\
\text { the past year }\end{array}$} & \multicolumn{4}{|c|}{ Olanzapine } & \multicolumn{4}{|c|}{ Quetiapine } & \multicolumn{4}{|c|}{ Risperidone } & \multicolumn{4}{|c|}{ Ziprasidone } \\
\hline & $\begin{array}{l}\text { Odds } \\
\text { ratio }\end{array}$ & $\begin{array}{l}\mathrm{Cl}- \\
\text { lower }\end{array}$ & $\begin{array}{l}\mathrm{Cl}- \\
\text { upper }\end{array}$ & $\begin{array}{l}p- \\
\text { value }\end{array}$ & $\begin{array}{l}\text { Odds } \\
\text { ratio }\end{array}$ & $\begin{array}{l}\mathrm{Cl}- \\
\text { lower }\end{array}$ & $\begin{array}{l}\mathrm{Cl}- \\
\text { upper }\end{array}$ & $\begin{array}{l}p- \\
\text { value }\end{array}$ & $\begin{array}{l}\text { Odds } \\
\text { ratio }\end{array}$ & $\begin{array}{l}\mathrm{Cl}- \\
\text { lower }\end{array}$ & $\begin{array}{l}\mathrm{Cl}- \\
\text { upper }\end{array}$ & $\begin{array}{l}p- \\
\text { value }\end{array}$ & $\begin{array}{l}\text { Odds } \\
\text { ratio }\end{array}$ & $\begin{array}{l}\mathrm{Cl}- \\
\text { lower }\end{array}$ & $\begin{array}{l}\mathrm{Cl}- \\
\text { upper }\end{array}$ & $\begin{array}{l}p \text { - } \\
\text { value }\end{array}$ \\
\hline Diabetes & 0.477 & 0.428 & 0.531 & $<.0001$ & 0.771 & 0.718 & 0.828 & $<.0001$ & 0.856 & 0.789 & 0.929 & .0002 & 1.05 & 0.939 & 1.174 & .3945 \\
\hline Obesity & 0.352 & 0.305 & 0.407 & $<.0001$ & 0.657 & 0.602 & 0.716 & $<.0001$ & 0.607 & 0.547 & 0.675 & $<.0001$ & 1.109 & 0.974 & 1.262 & .1181 \\
\hline Hyperlipidemia & 0.686 & 0.632 & 0.744 & $<.0001$ & 0.857 & 0.808 & 0.91 & $<.0001$ & 0.838 & 0.781 & 0.898 & $<.0001$ & 0.944 & 0.855 & 1.041 & .2469 \\
\hline $\begin{array}{l}\text { Substance } \\
\text { abuse }\end{array}$ & 1.321 & 1.23 & 1.417 & $<.0001$ & 1.363 & 1.288 & 1.442 & $<.0001$ & 1.216 & 1.14 & 1.298 & $<.0001$ & 0.987 & 0.896 & 1.088 & .7917 \\
\hline Sleep disorder & 0.860 & 0.695 & 1.065 & .1666 & 1.158 & 0.991 & 1.353 & .0655 & 0.794 & 0.654 & 0.965 & .0204 & 1.05 & 0.809 & 1.362 & .7140 \\
\hline $\begin{array}{l}\text { Cardiac } \\
\text { dysrhythmia }\end{array}$ & 1.422 & 1.137 & 1.778 & .0020 & 0.971 & 0.800 & 1.179 & .7690 & 1.116 & 0.9 & 1.385 & .3166 & 0.725 & 0.505 & 1.042 & .0825 \\
\hline
\end{tabular}

each year. Time trends suggest that this growth rate was remarkably steady from 2004 to 2010 , with no year seeing fewer than 5,000 or more than 7,000 new initiations. Given a roughly parallel increase in the overall bipolar population treated within VA, the proportion of individuals with bipolar disorder receiving an SGA prescription in a given year rose from $59 \%$ in 2003 to $75 \%$ in 2008 with a slight decrease to $72 \%$ in 2010 . These increases in use may have in part been driven by recent treatment guidelines that suggest SGAs as potential first-line treatments for multiple phases of bipolar disorder $[15,16]$. This decrease in overall use after 2008 may in part reflect effects of toxicity warnings on prescribing practices from the middle 2000's [43]. Regarding specific SGAs, use of aripiprazole, quetiapine, and ziprasidone increased over time while use of olanzapine and risperidone declined. Among providers with prescription privileges treating patients with bipolar disorder, the proportion using SGAs shrunk somewhat over the course of the study (from $90 \%$ to $86 \%$ ), though still encompasses the vast majority of potential prescribers.

A novel innovation in these analyses is the use of GLM techniques to investigate factors that affect provider decision-making on a month-by-month basis, to focus on clinical data available to prescribing clinicians. These analyses revealed that, while the number of new initiators each year remained relatively steady, the odds of initiating an SGA actually decreased slightly over the course of the study ( $\mathrm{OR}=.988$ annually). Additionally, two related factors emerged as key in predicting initiation of SGAs. First, SGA initiation was more common overall for patients who appeared more clinically complex. Second, over time SGA use appeared to be spreading to those with less complex clinical profiles.

\section{SGA initiation more common for clinically complex patients}

Providers were more likely to initiate SGAs for patients who were generally more psychiatrically ill at the time of their prescription (i.e. more likely to have a history of psychiatric hospitalization, recent psychotic features, or recent sleep disorder diagnosis); this is consistent with our finding that those who received an SGA also-at some time during the study period-received another antimanic (Table 1). However, on a month-by-month basis, prescriptions of other antimanics were less likely prior to initiation of SGAs. One interpretation is that those not receiving SGAs were already effectively controlled by a non-SGA medication. However, it is also possible that SGAs are being increasingly utilized as first-line treatments, bypassing other medications. Definitive answer awaits finer-grained treatment trajectory analyses.

\section{SGA initiation spreading to less clinically complex cases}

Time trend analyses indicate that, even though SGA initiation was more common for more complex cases as above, there was a broadening over time of the use of SGAs to include less clinically complex populations. Specifically, variable-by-time interaction terms indicated that SGA initiation became increasingly common for those with bipolar type II/NOS, those with no concurrent antimanic prescription, and those with no prior psychiatric hospitalization. This suggests that over time VA providers may have become increasingly comfortable prescribing SGAs for less severe portions of the bipolar population, though more provider-specific quantitative or qualitative data will be needed to draw firm conclusions.

\section{Other factors related to SGA initiation}

Most patient demographic covariates showed only modest associations with SGA initiation. African American patients were somewhat more likely to be given an initial SGA prescription during the study period compared to Whites, which is broadly in line with another VA study which found slightly but nonsignificantly higher rates of SGA use among African Americans (52\%) compared to others (44\%) with bipolar disorder [34]. Given evidence from previous studies that racial differences in SGA prescriptions may be closing [35], future studies should 
consider including race by time interaction terms in their statistical analyses.

The effects of medical comorbidities on SGA initiation appeared relatively small when results for all SGAs were combined, which makes intuitive sense given the heterogeneity of cardiometabolic risk profiles among the SGAs we studied. As expected, certain medical comorbidities were associated with substantial differences in prescribing practices for specific SGAs. Notably, individuals with preexisting diabetes, obesity, or hyperlipidemia were less likely to receive those SGAs with more prominent cardiometabolic effects (olanzapine, quetiapine and risperidone). Patients with substance abuse, in contrast, were more likely to receive these drugs: the sedating effects of these SGAs may be seen as desirable in treating patients with substance abuse disorders in whom benzodiazepines are considered inadvisable [39]. Contrary to expectations, quetiapine was not statistically more likely to be prescribed than aripiprazole for individuals with sleep disorders. It should be noted, however, that providers would only be likely to provide a sleep disorder diagnosis if a patient's sleep troubles occurred independently of their bipolar condition (e.g. sleep apnea), which may reflect a complex population in whom sedating drugs would be avoided.

Regional variation in SGA initiation after controlling for covariates was marked by higher rates of SGA use in the South. Veterans in this region of the country have lower self-reported mental and physical quality of life than other regions, perhaps reflecting poorer clinical course or sociodemographic differences [40,44]. However, analyses both in this bipolar population and among veterans with PTSD [39] indicate prominent regional variation despite extensive control for demographic and clinical characteristics. This finding may thus reflect regional differences in provider practice patterns, commonly reported across many health domains [45].

\section{Limitations}

Although administrative data provided a very large sample ( $n>125,000$ patients), it has the disadvantage of relying upon clinicians' diagnostic coding accuracy. Some conditions (e.g. obesity, sleep disturbance) may have been present and influenced treatment decisions and yet not been coded by clinicians. Similarly, codes for bipolar mixed episodes were not reliably utilized, although patients suffering mixed manic and depressive symptoms may be more responsive to SGAs than to other antimanic medications [46-48]. Furthermore, we could not include data on non-VA prescribing. In addition, we opted to approach these analyses primarily as class analyses, although we secondarily conducted $a$ priori analyses on specific SGAs and specific clinical correlates. Our current analyses did not include data on provider variables (e.g. demographics, academic affiliation, training background), but this is a clear direction for future research. Finally, our primary comparison was between patients initiating SGAs and those not initiating SGAs; we did not conduct additional analyses with different comparison groups (e.g. patients initiating lithium or other antimanics). Future research on SGA initiation exploring provider-level variables and using these other comparison groups would help shed further light on prescribers' initial medication decision for bipolar disorder.

\section{Conclusions}

Increase in SGA initiation within VA appears to be driven by an increase in the bipolar population rather than increasing rates of use of these drugs. Our month-by-month analyses, however, indicated that initiation rates are related to three factors: clinical complexity, spread of SGAs to less severe patients over time, and geographic variation that cannot be accounted for by our extensive list of covariates. Assessing the clinical appropriateness of SGA use is beyond the scope of these analyses, and must be judged in the context of the evolving clinical evidence base as applied to individual patients at the time of specific treatment decisions. However, the regional heterogeneity in particular suggests that social [49] or administrative [50] factors may play a role in the spread of SGAs for bipolar disorder. Thus, attention at the clinical, administrative, and policy levels may be warranted to ensure that utilization of SGAs is driven primarily by evidence and patient need rather than other factors.

Abbreviations

SGA: Second-generation antipsychotic; VA: Department of Veterans Affairs.

\section{Competing interests}

The authors declare that they have no competing interests.

\section{Authors' contributions}

CJM took a lead role in drafting and editing the manuscript. ML served as the lead statistician. RB participated in the conceptualization and design of the study. AFL assisted with statistical analyses. EGS and DNO assisted with the drafting and revision of the manuscript. LB played a lead role in operationalizing and refining our medication categories. MSB participated in the conceptualization and design of the study, and assisted with the drafting and revision of the manuscript. All authors read and approved the final manuscript.

\section{Acknowledgements}

This study was funded by the Department of Veterans Affairs, Veterans Health Administration, Office of Research and Development, Health Services Research \& Development grant \#IIR-10-314, "Spatiotemporal Spread of Newer Antipsychotics for Bipolar Disorder and PTSD." The funding organization provided competitive grant support for these analyses but was not otherwise involved in the design or conduct of the study, or review or approval of this manuscript. The opinions expressed in this manuscript represent the views of the authors and do not necessarily reflect the views of the Department of Veterans Affairs. These data have not yet been presented at a scientific meeting. Special thanks to Samuel S. Nordberg, PhD and Fang Zhang, PhD for their help in preparing this manuscript. 


\section{Author details}

${ }^{1}$ The Center for Healthcare Organization and Implementation Research, VA Boston Healthcare System and Edith Nourse Rogers Memorial VA Medical Center, Bedford, MA, USA. ${ }^{2}$ Department of Psychiatry, Harvard Medical School, Boston, MA, USA. ${ }^{3}$ Department of Mathematical Sciences, Bentley University, Waltham, MA, USA. ${ }^{4}$ Group Health Research Institute, Seattle, WA USA. ${ }^{5}$ Department of Health Services Research, University of Washington, Seattle, WA, USA. ${ }^{6}$ Research Center for Medical Statistics and Actuarial Science, Xi'an University of Finance and Economics, Xi'an, China. ${ }^{7}$ Massachusetts General Hospital, Boston, MA, USA. ${ }^{8}$ Department of Psychiatry, University of Massachusetts Medical School, Worcester, MA, USA.

VA Boston Healthcare System, Brockton, MA, USA.

Received: 14 March 2014 Accepted: 17 November 2014

Published online: 30 November 2014

\section{References}

1. Andlin-Sobocki P, Wittchen HU: Cost of affective disorders in Europe. Eur J Neurol 2005, 12(Suppl 1):34-38

2. Baldessarini RJ, Tondo L: Suicide risk and treatments for patients with bipolar disorder. JAMA 2003, 290(11):1517-1519.

3. Peele $\mathrm{PB}, \mathrm{X} \cup \mathrm{Y}, \mathrm{Kupfer} \mathrm{DJ}$ : Insurance expenditures on bipolar disorder: clinical and parity implications. Am J Psychiatry 2003, 160(7):1286-1290

4. Mitchell PB, Hadzi-Pavlovic D: Lithium treatment for bipolar disorder Bull World Health Organ 2000, 78(4):515-517.

5. Hirschfeld RMA, Kasper S: A review of the evidence for carbamazepine and oxcarbazepine in the treatment of bipolar disorder. Int $J$ Neuropsychopharmacology 2004, 7(4):507-522.

6. McElroy SL, Keck PE Jr, Pope HG Jr, Hudson JI: Valproate in the treatment of bipolar disorder: literature review and clinical guidelines. J Clin Psychopharmacol 1992, 12(1 Suppl):42S-52S.

7. Hirschfeld R, Bowden CL, Gitlin MJ, Keck PE, Suppes T, Thase ME, Perlis RH: Practice guideline for the treatment of patients with bipolar disorder (revision). Am J Psychiatry 2002, 159(4 Suppl):1-50

8. Yatham LN, Kennedy SH, Parikh SV, Schaffer A, Beaulieu S, Alda M, O'Donovan C, Macqueen G, McIntyre RS, Sharma V, Ravindran A, Young LT, Milev R, Bond DJ, Frey BN, Goldstein BI, Lafer B, Birmaher B, Ha K, Nolen WA Berk M: Canadian Network for Mood and Anxiety Treatments (CANMAT) and International Society for Bipolar Disorders (ISBD) collaborative update of CANMAT guidelines for the management of patients with bipolar disorder: update 2013. Bipolar Disord 2013, 15(1):1-44.

9. VA/DoD: Management of Bipolar Disorder in Adults (BD). Washington, D. C: Department of Veterans Affairs and Department of Defense; 2010.

10. NICE: Bipolar Disorder: The Management of Bipolar Disorder in Adults, Children and Adolescents, in Primary and Secondary Care. London: National Institute for Health and Clinical Excellence; 2006.

11. Scherk H, Pajonk FG, Leucht S: Second-generation antipsychotic agents in the treatment of acute mania: a systematic review and meta-analysis of randomized controlled trials. Arch Gen Psychiatry 2007, 64(4):442-455

12. Cruz N, Sanchez-Moreno J, Torres F, Goikolea JM, Valenti M, Vieta E: Efficacy of modern antipsychotics in placebo-controlled trials in bipolar depression: a meta-analysis. Int J Neuropsychopharmacol 2010, 13(1):5-14.

13. De Fruyt J, Deschepper E, Audenaert K, Constant E, Floris M, Pitchot W, Sienaert P, Souery D, Claes S: Second generation antipsychotics in the treatment of bipolar depression: a systematic review and meta-analysis. J Psychopharmacol 2012, 26(5):603-617.

14. Smith LA, Cornelius V, Warnock A, Bell A, Young AH: Effectiveness of mood stabilizers and antipsychotics in the maintenance phase of bipolar disorder: a systematic review of randomized controlled trials. Bipolar Disord 2007, 9(4):394-412.

15. Nivoli AM, Murru A, Goikolea JM, Crespo JM, Montes JM, Gonzalez-Pinto A, Garcia-Portilla P, Bobes J, Saiz-Ruiz J, Vieta E: New treatment guidelines for acute bipolar mania: a critical review. J Affect Disord 2012 140(2):125-141.

16. Nivoli AM, Colom F, Murru A, Pacchiarotti I, Castro-Loli P, Gonzalez-Pinto A Fountoulakis KN, Vieta E: New treatment guidelines for acute bipolar depression: a systematic review. J Affect Disord 2011, 129(1-3):14-26.

17. Pillarella J, Higashi A, Alexander GC, Conti R: Trends in use of secondgeneration antipsychotics for treatment of bipolar disorder in the United States, 1998-2009. Psychiatr Serv 2012, 63(1):83-86.
18. Leucht S, Corves C, Arbter D, Engel RR, Li C, Davis JM: Second-generation versus first-generation antipsychotic drugs for schizophrenia: a meta-analysis. Lancet 2009, 373(9657):31-41.

19. Reist C, Mintz J, Albers LJ, Jamal MM, Szabo S, Ozdemir V: Secondgeneration antipsychotic exposure and metabolic-related disorders in patients with schizophrenia: an observational pharmacoepidemiology study from 1988 to 2002. J Clin Psychopharmacol 2007, 27(1):46-51.

20. Newcomer JW: Second-generation (atypical) antipsychotics and metabolic effects: a comprehensive literature review. CNS Drugs 2005, 19(Suppl 1):1-93.

21. Guo JJ, Keck PE Jr, Corey-Lisle PK, Li H, Jiang D, Jang R, L'Italien GJ: Risk of diabetes mellitus associated with atypical antipsychotic use among patients with bipolar disorder: A retrospective, population-based, case-control study. J Clin Psychiatry 2006, 67(7):1055-1061

22. Law MR, Ross-Degnan D, Soumerai SB: Effect of prior authorization of second-generation antipsychotic agents on pharmacy utilization and reimbursements. Psychiatr Serv 2008, 59(5):540-546.

23. Herbeck DM, West JC, Ruditis I, Duffy FF, Fitek DJ, Bell CC, Snowden LR: Variations in use of second-generation antipsychotic medication by race among adult psychiatric patients. Psychiatr Serv 2004, 55(6):677-684.

24. Copeland LA, Zeber JE, Valenstein M, Blow FC: Racial disparity in the use of atypical antipsychotic medications among veterans. Am J Psychiatry 2003, 160(10):1817-1822

25. Opolka JL, Rascati KL, Brown CM, Gibson PJ: Ethnicity and prescription patterns for haloperidol, risperidone, and olanzapine. Psychiatr Serv 2004 55(2):151-156

26. Valenstein M, McCarthy JF, Ignacio RV, Dalack GW, Stavenger T, Blow FC Patient- and facility-level factors associated with diffusion of a new antipsychotic in the VA health system. Psychiatr Serv 2006, 57(1):70-76.

27. Wang PS, West JC, Tanielian T, Pincus HA: Recent patterns and predictors of antipsychotic medication regimens used to treat schizophrenia and other psychotic disorders. Schizophr Bull 2000, 26(2):451-457.

28. Yang M, Barner JC, Lawson KA, Rascati KL, Wilson JP, Crismon ML, Worchel J Mascarenas CA: Antipsychotic medication utilization trends among Texas veterans: 1997-2002. Ann Pharmacother 2008, 42(9):1229-1238.

29. Kreyenbuhl J, Zito JM, Buchanan RW, Soeken KL, Lehman AF: Racial disparity in the pharmacological management of schizophrenia. Schizophr Bull 2003, 29(2):183-193.

30. Kuno $E$, Rothbard AB: Racial disparities in antipsychotic prescription patterns for patients with schizophrenia. Am J Psychiatry 2002, 159(4):567-572.

31. Owen RR, Feng W, Thrush CR, Hudson TJ, Austen MA: Variations in prescribing practices for novel antipsychotic medications among Veterans Affairs hospitals. Psychiatr Serv 2001, 52(11):1523-1525.

32. Mark TL, Dirani R, Slade E, Russo PA: Access to new medications to treat schizophrenia. J Behav Health Serv Res 2002, 29(1):15-29.

33. Garver D, Lazarus A, Rajagopalan K, Lamerato L, Katz LM, Stern LS, Dolgitser M, Doyle JJ: Racial differences in medication switching and concomitant prescriptions in the treatment of bipolar disorder. Psychiatr Serv 2006, 57(5):666-672

34. Kilbourne AM, Pincus HA: Patterns of psychotropic medication use by race among veterans with bipolar disorder. Psychiatr Serv 2006, 57(1):123-126

35. Daumit GL, Crum RM, Guallar E, Powe NR, Primm AB, Steinwachs DM, Ford DE: Outpatient prescriptions for atypical antipsychotics for African Americans, Hispanics, and whites in the United States. Arch Gen Psychiatry 2003, 60(2):121-128

36. Connolly A, Taylor D, Sparshatt A, Cornelius V: Antipsychotic prescribing in Black and White hospitalised patients. J Psychopharmacol (Oxf) 2011, 25(5):704-709.

37. Connolly A, Taylor D: Ethnicity and quality of antipsychotic prescribing among in-patients in south London. Br J Psychiatry 2008, 193(2):161-162.

38. Goren JL, Meterko M, Williams S, Young GJ, Baker E, Chou CH, Kilbourne AM, Bauer MS: Antipsychotic prescribing pathways, polypharmacy, and clozapine use in treatment of schizophrenia. Psychiatr Serv 2013, 64(6):527-533.

39. Bauer MS, Lee A, Li M, Bajor LA, Rasmusson A, Kazis LE: Off-label use of second generation antipsychotics for post-traumatic stress disorder in the Department of Veterans Affairs: Time trends and sociodemographic, comorbidity, and regional correlates. Pharmacoepidemiology and Drug Safety 2013 , in press 
40. Kazis LE, Miller DR, Skinner KM, Lee A, Ren XS, Clark JA, Rogers WH, lii AS, Selim A, Linzer M, Payne SMC, Mansell D, Fincke GB: Applications of methodologies of the Veterans Health Study in the VA healthcare system: conclusions and summary. J Ambulatory Care Manage 2006, 29(2):182-188.

41. Kazis LE: Health outcome assessments in medicine: history, applications, and new directions. Adv Intern Med 1991, 36:109-130.

42. Marder SR, McQuade RD, Stock E, Kaplita S, Marcus R, Safferman AZ, Saha A, Ali M, Iwamoto T: Aripiprazole in the treatment of schizophrenia: safety and tolerability in short-term, placebo-controlled trials. Schizophr Res 2003, 61(2-3):123-136.

43. Dorsey ER, Rabbani A, Gallagher SA, Conti RM, Alexander GC: Impact of FDA black box advisory on antipsychotic medication use. Arch Intern Med 2010, 170(1):96-103.

44. Kazis LE, Nethercot VA, Ren XS, Lee A, Selim A, Miller DR: Medication effectiveness studies in the United States Veterans Administration health care system: a model for large integrated delivery systems. Drug Dev Res 2006, 67(3):217-226.

45. Wennberg JE: Time to tackle unwarranted variations in practice. BMJ 2011, 342.

46. Fountoulakis KN, Kontis D, Gonda X, Siamouli M, Yatham LN: Treatment of mixed bipolar states. Int J Neuropsychopharmacol 2012, 15(7):1015-1026.

47. Mclntyre RS, Yoon J: Efficacy of antimanic treatments in mixed states. Bipolar Disord 2012, 14(Suppl 2):22-36.

48. Swann AC, Lafer B, Perugi G, Frye MA, Bauer M, Bahk WM, Scott J, Ha K, Suppes T: Bipolar mixed states: an international society for bipolar disorders task force report of symptom structure, course of illness, and diagnosis. Am J Psychiatry 2013, 170(1):31-42.

49. Rogers EM: Diffusion of innovations: Simon and Schuster; 2010

50. Dearing JW: Applying diffusion of innovation theory to intervention development. Res Soc Work Pract 2009, 19(5):503-518.

\section{Submit your next manuscript to BioMed Central and take full advantage of:}

- Convenient online submission

- Thorough peer review

- No space constraints or color figure charges

- Immediate publication on acceptance

- Inclusion in PubMed, CAS, Scopus and Google Scholar

- Research which is freely available for redistribution 